\title{
Physicians' perspectives on the treatment of osteoporosis patients with bisphosphonates
}

\author{
This article was published in the following Dove Press journal: \\ Clinical Interventions in Aging \\ 15 February 2016 \\ Number of times this article has been viewed
}

\author{
Tao Gu' \\ Debra F Eisenberg \\ Lawrence' \\ Judith J Stephenson' \\ Jingbo $\mathrm{Yu}^{2}$ \\ 'HealthCore, Wilmington, DE, \\ ${ }^{2}$ Merck \& Co., Inc., Kenilworth, \\ NJ, USA
}

Correspondence: Tao Gu HealthCore, 123 Justison Street, Suite 200, Wilmington, DE I980I, USA

$\mathrm{Tel}+\mathrm{I} 3022302000$

Fax + I 3022302020

Email tgu@healthcore.com
Background: Noncompliance with bisphosphonate therapy among osteoporosis patients attenuates the reduction of fracture risk. The objective of this study was to assess physicians' prescribing considerations, preferences for osteoporosis treatments, and perceptions of patients' compliance with oral bisphosphonates.

Methods: This was an online survey of US physicians identified in the HealthCore Integrated Research Database (HIRD ${ }^{\mathrm{SM}}$ ) as prescribing oral bisphosphonates to women aged $\geq 55$ years. The survey gauged physicians' prescribing considerations and preferences for various types of osteoporosis medications. The physicians were asked to predict patient persistence and compliance, and rate various reasons for noncompliance.

Results: Bone mineral density, long-term medication use (eg, corticosteroids), and a history of fracture were ranked as major considerations by $94.9 \%, 88.6 \%$, and $86.7 \%$ of participating physicians $(\mathrm{N}=158)$, respectively, when deciding whether to treat an osteoporosis patient. Most physicians expressed a preference for prescribing weekly or monthly oral bisphosphonates, for both newly diagnosed patients (54.4\% and $34.2 \%$, respectively) and long-term users of oral bisphosphonates (40.5\% and 36.1\%, respectively). Most physicians (23.4\% always, 58.9\% sometimes) incorporated a drug holiday into their prescribing patterns. Although most physicians predicted that more than half of the patients would comply with the prescribed medication for at least a year, $17.7 \%$ predicted that less than half of the patients would be compliant in the 1 st year, and $29.7 \%$ predicted the same result for compliance beyond 1 year. In the opinion of the majority of physicians, the major reasons for noncompliance with oral bisphosphonates were intolerance of a medication due to a gastrointestinal condition (71.5\%) and medication side effects $(69.6 \%)$.

Conclusion: US physicians consider several relevant risk factors when deciding whether to prescribe pharmacotherapy and exhibit a preference for weekly or monthly regimens. The physicians estimated a substantial minority of the patients to be noncompliant with oral bisphosphonates, for reasons including primarily gastrointestinal intolerance and medication-related side effects.

Keywords: osteoporosis, bisphosphonates, physician's practice patterns, cross-sectional studies, patient compliance

\section{Background}

Osteoporosis is a deterioration of bone mass determined by dual-energy X-ray absorptiometry that affects $16 \%$ of US women aged $\geq 50$ years, ${ }^{1}$ increasing their risk of fracture. National guidelines recommend pharmacological treatment for specific groups of postmenopausal women at increased risk of fracture, including those with low bone mineral density (BMD; defined as a T-score $\leq-2.5){ }^{2-4}$ The recommended first-line treatment, oral bisphosphonate therapy has been shown to decrease the risk of vertebral and hip fractures. ${ }^{2}$ Bisphosphonate treatment should be long-term, ie,

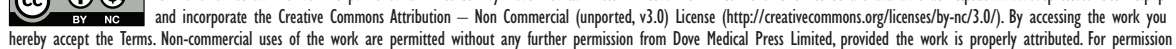
for commercial use of this work, please see paragraphs 4.2 and 5 of our Terms (https://www.dovepress.com/terms.php). 
3 to 5 years, after which some guidelines allow for a drug holiday (ie, a scheduled break in treatment) in patients whose treatment is successful (defined as stable or increasing BMD and no fractures $)^{3}$ or who are deemed to be at low risk for a fracture. ${ }^{4}$

Earlier studies indicate that effective fracture prevention has been hindered by the suboptimal prescribing of bisphosphonates to high-risk women ${ }^{5,6}$ and the low rates of persistence and compliance among women who have been prescribed bisphosphonates. ${ }^{7,8}$ There is also no consensus on the need for or benefits of a drug holiday. Adverse effects associated with long-term bisphosphonate use are rare, ${ }^{9}$ and evidence is mixed regarding the risk of fracture after discontinuation. ${ }^{10,11}$

Information from physicians on their practices regarding anti-osteoporosis therapy is scarce. Earlier US physician surveys focused on the effects of fracture risk, treatment efficacy, and treatment cost on physicians' rate of recommendation of pharmacotherapy; ${ }^{12,13}$ changes in risk assessment methods and treatment rates over time; ${ }^{14}$ and comparison of adherence rates predicted by physicians with the actual adherence rates of their patients. ${ }^{15}$ None of these studies provided information on physicians' therapy preferences or their use of drug holidays, and none contained data more recent than 2008. We sought an updated characterization of the perspectives of physicians on the issues surrounding treatment of osteoporosis patients. The objectives of this study were to assess physicians' oral bisphosphonate prescribing practices, including their use of drug holidays, and to determine their preferred drug therapies and their perceptions of patient compliance.

\section{Methods}

\section{Study design and physician selection}

The study design consisted of an online survey of US physicians identified as prescribers of oral bisphosphonates to women aged $\geq 55$ years. Eligible physicians were identified from claims in the HealthCore Integrated Research Database $\left(\mathrm{HIRD}^{\mathrm{SM}}\right)$, a large administrative claims database containing medical and pharmacy claims and eligibility data from 14 geographically dispersed US health plans.

Physicians were selected for inclusion based on the administrative claims of their patients. Women aged $\geq 55$ years with $\geq 1$ pharmacy claim for an oral bisphosphonate (ie, alendronate, risedronate, or ibandronate) and no claims for Paget's disease or malignant neoplasm between January 1, 2007 and July 30, 2009 were first identified. The physician most frequently visited by each of these women (for osteoporosis, as indicated by the appropriate diagnosis code in the medical claim) was identified, and a random sample of these physicians $(\mathrm{N}=7,500)$ was sent to the survey vendor (ORC International, Cincinnati, OH, USA).

Invitations to participate in the survey were faxed in November 2014 to eligible physicians and contained a link to the survey website, which remained active for 21 days after the date of the invitation. A single reminder letter was faxed during this 21-day period to the physicians who had not yet responded. Based on an expected margin of error of $8.7 \%$, a sample size of 150 completed surveys was predetermined to be sufficient for the desired analyses, and the survey portal was closed when this number of completed surveys was attained. All participating physicians gave informed written consent. The physician selection protocol and the survey were approved by the New England Institutional Review Board.

\section{Survey instrument}

The survey was developed by HealthCore and the study sponsor based on a review of the literature and consisted of 22 questions gauging physicians' prescribing considerations, preferences for various types of osteoporosis medications, actual prescribing practices, and perceptions of patient treatment acceptability and treatment compliance. Physician demographic and practice characteristics, eg, sex, age, specialty, type of practice, and years in practice were also collected.

The physicians were shown a list of eleven items and asked to rate them as a major or minor consideration, or not a consideration, when deciding to treat a female osteoporosis patient with an oral bisphosphonate. The list was as follows: family history (eg, fragility fracture or osteoporosis in a first-degree relative), body frame size, lifestyle factors (eg, poor diet, physical inactivity, smoking, excessive alcohol consumption, low body weight, lack of sunlight), history of fracture as an adult, long-term use of corticosteroids and other medications (eg, anti-seizure medications, DepoProvera, aromatase inhibitors), hormone levels (eg, estrogen deficiency, thyroid problems, overactive parathyroid/adrenal glands), patient's health/frailty (eg, whether a patient is able to stand up for a while after taking osteoporosis medication), BMD, patient's race/ethnicity, age at menstruation and/or menopause, and comorbidity history (eg, gastrointestinal condition, renal impairment).

Next, physicians were asked to select oral (daily, weekly, or monthly), infusion/intravenous, or injectable regimens as the preferred treatment for newly diagnosed female osteoporosis patients and for female osteoporosis patients who have been treated long-term ( 2 years or more) with oral bisphosphonates. 
The physicians were queried regarding how many months of oral bisphosphonate therapy they felt was required for the medication to be effective in reducing the risk of fracture ( $<3$ months; 3 to $<6$ months; 6 to $<12$ months; 12 to $<15$ months; 15 to $<18$ months; 18 to $<24$ months; 24 to $<36$ months; $\geq 36$ months); whether they ever recommended stopping treatment or drug holidays (yes, always; yes, sometimes; no), and if so, at what time point (after $\leq 1$ year of bisphosphonate medication persistence and compliance; after 1 year; after 2 years; after 3 years; after 4 years; after 5 years; after $\geq 6$ years; no specific time, it depends on the patient); and the main reasons for recommending a drug holiday (eg, research indicates that drug holidays are necessary; patient expresses concerns about medication side effects; drug holidays are beneficial to patient treatment patterns; patient expresses other concern about taking medication). They were also asked whether they had any concerns (yes/no) about oral bisphosphonates that affected their prescribing practices.

The physicians rated the acceptability of oral bisphosphonates to their patients on a scale of 0 to $10(0$, completely unacceptable; 10 , completely acceptable), and then estimated their patients' persistence and compliance for time periods of 1 year and more than 1 year. Persistence was defined as taking the medication for a specific period (eg, 1 year) with no gaps in therapy of 2 months or longer. Compliance was defined as taking the medication for a specific period and following dosing instructions at least $70 \%$ of the time. Both persistence and compliance were estimated as the percentage of patients expected to persist or comply, in categories of 10 percentage points each (ie, $0 \%-9 \%, 10 \%-19 \%$ ). Finally, physicians were asked i) to rate potential reasons for their patients' noncompliance as major, minor, or not a reason and ii) to select one or more items from a list of methods used to monitor their patients' compliance.

\section{Statistical analysis}

This was a descriptive study and no statistical analyses were planned or performed. The data are presented as numbers and percentages of respondents, or a combination thereof. All analyses were conducted using SAS version 9.2 (SAS Institute Inc., Cary, NC, USA).

\section{Results}

\section{Participating physicians}

A total of 12,297 physicians were identified and a random sample of these was invited to participate in the study. Of the 7,500 physicians receiving an invitation, 158 completed the survey, eleven were screened but never started the survey, five started but did not finish the survey, 88 declined to participate, eleven were excluded because they no longer met study inclusion criteria, and the remaining 7,227 had not responded to the invitation at the time the survey portal was closed. The cooperation rate, defined as the number of completed surveys divided by the number of completed surveys, incomplete surveys, and refusals, at the time of the portal closure was $60.3 \%$.

Of the 158 physicians who completed the survey (one of whom neglected to provide demographic data), $77.7 \%$ were male, $67.5 \%$ were aged $45-60$ years, and $58.6 \%$ had 20 or more years in clinical practice (Table 1). Most were primary care physicians in either internal medicine (43.9\%) or general/family practice (34.4\%). The mean (standard deviation) number of osteoporosis patients per practice was

Table I Demographic and clinical characteristics of participating physicians

\begin{tabular}{|c|c|c|}
\hline Characteristic & $\mathbf{N}^{\mathbf{a}}$ & $\%$ \\
\hline \multicolumn{3}{|l|}{ Sex } \\
\hline Male & 122 & 77.7 \\
\hline Female & 35 & 22.3 \\
\hline \multicolumn{3}{|l|}{ Age group (years) } \\
\hline$<30$ & 0 & 0.0 \\
\hline $30-44$ & 21 & 13.4 \\
\hline $45-60$ & 106 & 67.5 \\
\hline$>60$ & 30 & 19.1 \\
\hline \multicolumn{3}{|l|}{ Geographic region } \\
\hline Northeast & 54 & 34.2 \\
\hline Midwest & 50 & 31.6 \\
\hline South & 11 & 7.0 \\
\hline West & 40 & 25.3 \\
\hline Other & 3 & 1.9 \\
\hline \multicolumn{3}{|l|}{ Years in practice } \\
\hline$<5$ & I & 0.6 \\
\hline 5 to $<10$ & 4 & 2.6 \\
\hline 10 to $<15$ & 19 & 12.1 \\
\hline 15 to $<20$ & 41 & 26.1 \\
\hline$\geq 20$ & 92 & 58.6 \\
\hline \multicolumn{3}{|l|}{ Current practice setting } \\
\hline Solo practice & 59 & 37.6 \\
\hline Group practice & 96 & $6 \mathrm{I} .1$ \\
\hline Some other arrangement & 2 & 1.3 \\
\hline \multicolumn{3}{|c|}{ Associated with an academic teaching center } \\
\hline Yes & 55 & 35.0 \\
\hline No & 102 & 65.0 \\
\hline \multicolumn{3}{|l|}{ Primary specialty } \\
\hline Primary care & 123 & 78.3 \\
\hline Internal medicine & 69 & 43.9 \\
\hline General or family practice & 54 & 34.4 \\
\hline Specialist & 32 & 20.4 \\
\hline Rheumatology & 22 & 14.0 \\
\hline Endocrinology & 10 & 6.4 \\
\hline Some other specialty & 2 & 1.3 \\
\hline
\end{tabular}

Note: ane physician failed to provide demographic data, except for geographic region. 
263 (191), and half of the physicians (49.4\%) reported that $50 \%$ or more of their patients with osteoporosis were being treated with oral bisphosphonates (data not shown).

\section{Prescription considerations and treatment preferences}

BMD, long-term medication use (eg, corticosteroids), and a history of fracture were ranked as major considerations by $94.9 \%, 88.6 \%$, and $86.7 \%$ of physicians, respectively, when deciding whether to treat a female osteoporosis patient with an oral bisphosphonate (Figure 1). Other factors rated as a major consideration by more than half of the physicians were the patient's health/frailty $(71.5 \%)$, the patient's comorbidity history $(60.8 \%)$, lifestyle factors $(60.1 \%)$, family history of fragility fracture or osteoporosis $(53.2 \%)$, and hormone levels $(51.9 \%)$.

Most physicians expressed a preference for prescribing weekly or monthly oral bisphosphonate therapy (Table 2), for both newly diagnosed female osteoporosis patients $(54.4 \%$ and $34.2 \%$, respectively) and long-term female users of oral bisphosphonates $(40.5 \%$ and $36.1 \%$, respectively).

\section{Prescribing practices}

Almost half of the physicians (45.0\%) thought that the fracture-risk reduction could be achieved between 6 and 15 months of treatment with bisphosphonates (Table 3 ).
Approximately the same percentage (46.2\%) thought that 18 months or more were required to achieve the fracture-risk reduction. Most physicians (23.4\% always, 58.9\% sometimes) incorporated a drug holiday into their prescribing practices (Table 3), citing i) research indicating that drug holidays are necessary (30.0\% of respondents) and ii) patient concerns about side effects (20.0\% of respondents) as the main reasons for this practice. Approximately half of the physicians $(53.2 \%)$ reported having concerns about bisphosphonates that affected their prescribing practices (data not shown).

\section{Physicians' perceptions of treatment acceptability and treatment compliance}

The majority of physicians $(\mathrm{N}=131 ; 82.9 \%)$ estimated that their patients would rate the acceptability of oral bisphosphonates as 5-8 on a $0-10$-point scale (Figure 2). Although most physicians predicted that more than half of the patients would comply with the prescribed medication for at least a year, $17.7 \%$ predicted that less than half of the patients would be compliant in the 1 st year, and $29.7 \%$ predicted the same result for compliance beyond 1 year (Figure 3). Physicians were slightly more optimistic about patient persistence (Figure 3). In the opinion of the majority of physicians, the major reasons for noncompliance were intolerance of a medication due to the gastrointestinal condition $(71.5 \%)$ and medication side effects (69.6\%; Figure 4).

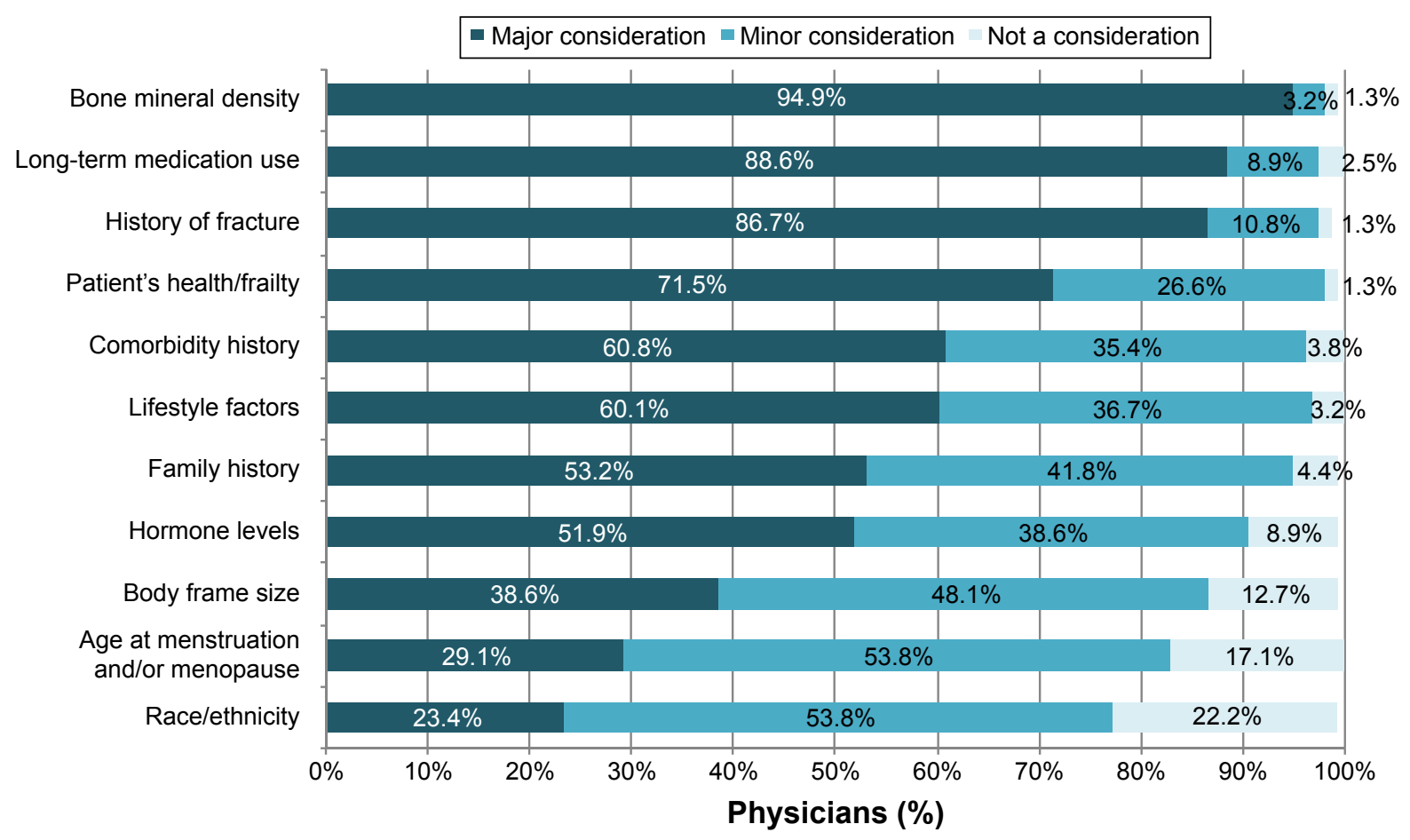

Figure I Considerations in physicians' decisions to treat female osteoporosis patients with oral bisphosphonates. Note: Missing answers are not presented in the figure, so some bars do not sum to $100 \%$. 
Table 2 Physicians' preferences for osteoporosis medication in female osteoporosis patients

\begin{tabular}{lllll}
\hline & $\begin{array}{l}\text { Newly } \\
\text { diagnosed } \\
\text { patients } \\
\text { (N, \%) }\end{array}$ & $\begin{array}{l}\text { Long-term } \\
\text { users of oral } \\
\text { BPs (N, \%) }\end{array}$ \\
\hline Daily oral BP drug therapy & I & 0.6 & 2 & 1.3 \\
Weekly oral BP drug therapy & 86 & 54.4 & 64 & 40.5 \\
Monthly oral BP drug therapy & 54 & 34.2 & 57 & 36.1 \\
Infusion/IV drug therapy & 7 & 4.4 & 12 & 7.6 \\
Injectable drug therapy & 10 & 6.3 & 23 & 14.6 \\
\hline
\end{tabular}

Abbreviations: BP, bisphosphonate; IV, intravenous.

Table 3 Length of oral bisphosphonate therapy and drug holidays

\begin{tabular}{|c|c|c|}
\hline Survey question & $\mathbf{N}$ & $\%$ \\
\hline \multicolumn{3}{|l|}{ Length of oral BP therapy physicians felt was } \\
\hline \multirow{2}{*}{\multicolumn{3}{|c|}{$\begin{array}{l}\text { required for the medication to be effective in } \\
\text { reducing the risk of fracture }\end{array}$}} \\
\hline & & \\
\hline Less than 3 months & 3 & 1.9 \\
\hline 3 to $<6$ months & 5 & 3.2 \\
\hline 6 to $<12$ months & 38 & 24.1 \\
\hline 12 to $<15$ months & 33 & 20.9 \\
\hline 15 to $<18$ months & 6 & 3.8 \\
\hline 18 to $<24$ months & 24 & 15.2 \\
\hline 24 to $<36$ months & 28 & 17.7 \\
\hline$\geq 36$ months & 21 & 13.3 \\
\hline \multicolumn{3}{|l|}{ Recommendation of a drug holiday/stopping the use } \\
\hline \multicolumn{3}{|l|}{ of BP therapy, for patients with osteoporosis who } \\
\hline \multicolumn{3}{|l|}{ are on oral BP therapy } \\
\hline Yes, always & 37 & 23.4 \\
\hline Yes, sometimes & 93 & 58.9 \\
\hline No & 28 & 17.7 \\
\hline \multirow{2}{*}{\multicolumn{3}{|c|}{$\begin{array}{l}\text { Length of time before recommending a drug holiday } \\
\text { for osteoporosis patients on oral BP therapy }\end{array}$}} \\
\hline & & \\
\hline After $<$ I year of persistence and compliance & 0 & 0.0 \\
\hline After I year of persistence and compliance & 7 & 5.4 \\
\hline After 2 years of persistence and compliance & 19 & 14.6 \\
\hline After 3 years of persistence and compliance & 13 & 10.0 \\
\hline After 4 years of persistence and compliance & 9 & 6.9 \\
\hline After 5 years of persistence and compliance & 68 & 52.3 \\
\hline After $>6$ years of persistence and compliance & 8 & 6.2 \\
\hline No specific time; it depends on the patient & 6 & 4.6 \\
\hline \multirow{2}{*}{\multicolumn{3}{|c|}{$\begin{array}{l}\text { Main reason for recommending a drug holiday for } \\
\text { osteoporosis patients on oral BP therapy }\end{array}$}} \\
\hline & & \\
\hline $\begin{array}{l}\text { Drug holidays are beneficial to patient treatment } \\
\text { patterns }\end{array}$ & 23 & 17.7 \\
\hline $\begin{array}{l}\text { Patient expresses concerns about medication } \\
\text { side effects }\end{array}$ & 26 & 20.0 \\
\hline $\begin{array}{l}\text { Patient expresses other concern about taking } \\
\text { medication }\end{array}$ & 15 & 11.5 \\
\hline $\begin{array}{l}\text { Research indicates that drug holidays are } \\
\text { necessary }\end{array}$ & 39 & 30.0 \\
\hline $\begin{array}{l}\text { Patient does not show sign of benefit from } \\
\text { medication }\end{array}$ & 8 & 6.2 \\
\hline Patient shows sign of benefit from medication & 8 & 6.2 \\
\hline Other reason & II & 8.5 \\
\hline
\end{tabular}

Note: aAmong 130 providers answering "yes" to QII. Abbreviation: BP, bisphosphonate.

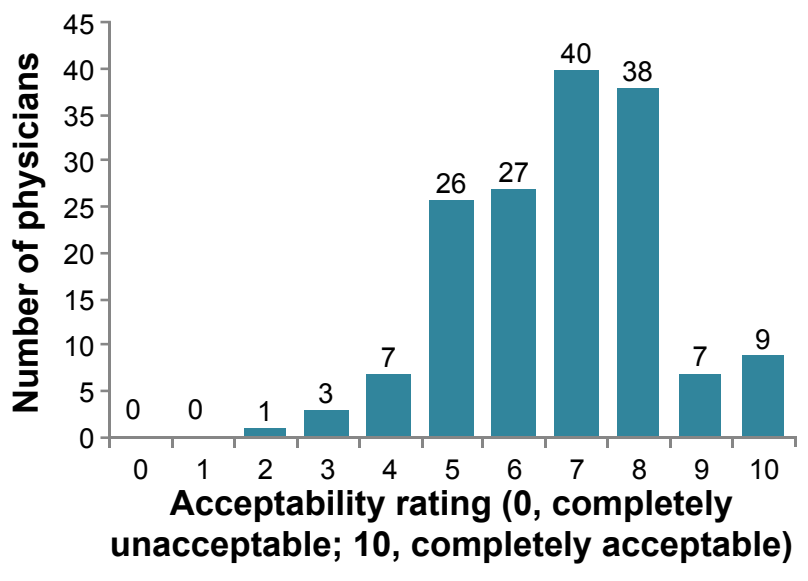

Figure 2 Physicians' ratings of patients' acceptability of oral bisphosphonate drug therapy.

When asked how they monitored their patients' compliance with prescribed oral bisphosphonates (data not shown), physicians' answers included asking about problems with medication (98.1\%), asking explicitly about compliance (95.6\%), and using dual-energy X-ray absorptiometers or other devices to measure the response to treatment (93.0\%). Less frequent methods of monitoring patient compliance were asking a family member or caregiver about compliance $(69.0 \%)$ and reviewing medical records or pharmacy data $(58.9 \%)$.

23.4

58.9

17.7

\section{.0}

Figure 3 Physicians' estimates of patients' persistence and compliance with oral bisphosphonates.

Notes: Persistence was defined as taking the medication for the specified period, with no gaps in therapy of 2 months or longer. Compliance was defined as taking the medication for the specified period and following dosing instructions at least $70 \%$ of the time. 


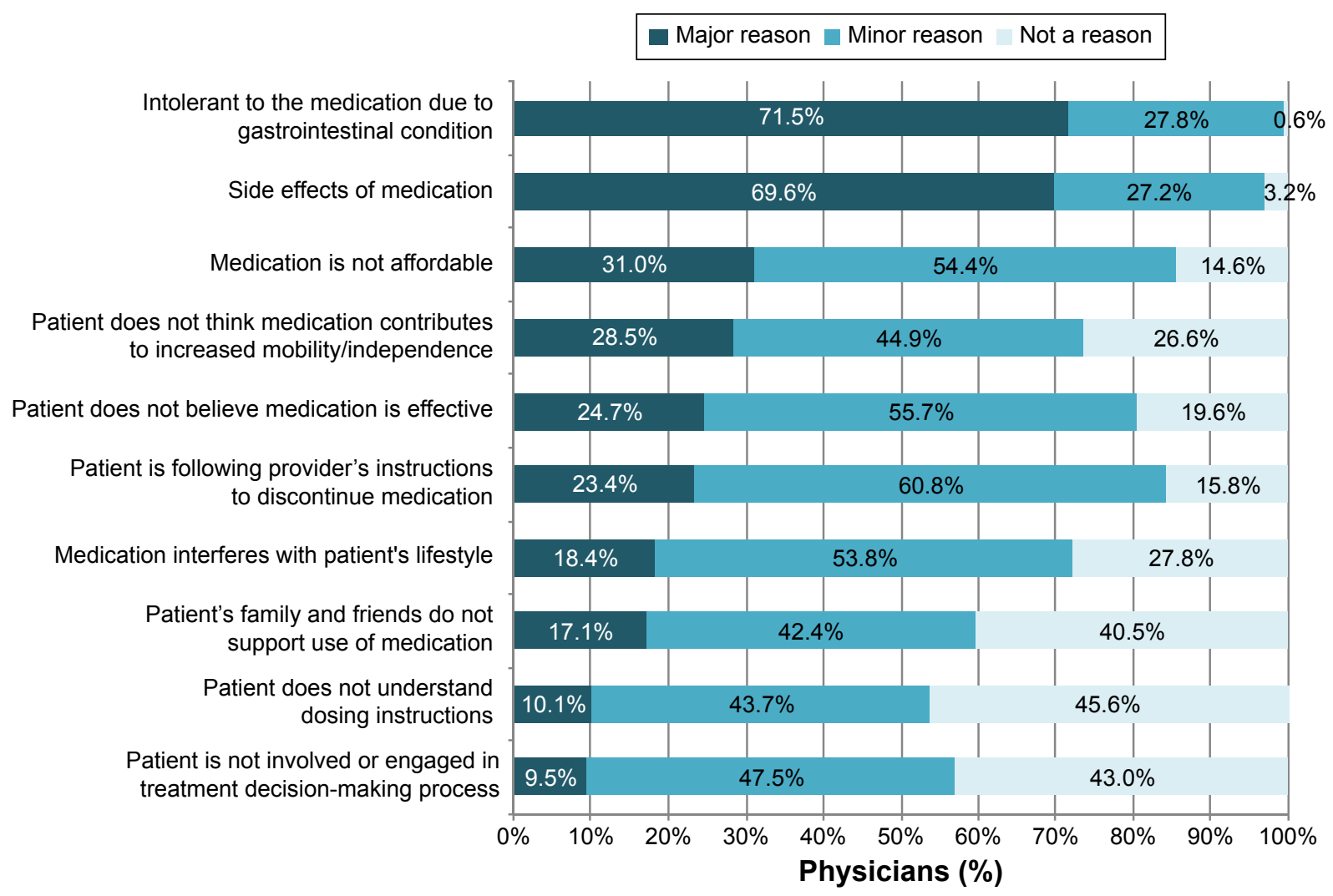

Figure 4 Physician-reported reasons for patients' noncompliance with oral bisphosphonates.

\section{Discussion}

This study of US physicians who regularly treated osteoporosis patients with oral bisphosphonates was designed to assess physicians' considerations and preferences when prescribing bisphosphonates, their usual prescribing practices, and their expectations and monitoring of patient compliance. The results show that, when prescribing bisphosphonates, physicians consider known risk factors for osteoporotic fracture and expect good compliance from their patients.

Earlier surveys of US physicians showed that T-scores influenced the recommendation of treatment ${ }^{12}$ and that the number of physicians assessing the patient history and performing BMD testing increased by 19 and 52 percentage points, respectively, between 1998 and 2006. ${ }^{14}$ In the current physician sample, BMD test results were a major consideration for almost all the physicians, as were patients' history of fracture and medication use. These major considerations are consistent with evidence that low bone mass and a history of fracture are associated with an increased risk of osteoporotic fracture. ${ }^{3}$ They also match the findings of the 2007 National Health and Wellness Survey, in which an earlier BMD test and fracture history were predictive of pharmacologic treatment of osteoporotic or osteopenic women aged $\geq 40 .{ }^{6}$ In addition, our results were similar to those reported in a survey of members of the Korean Society for Bone and Mineral Research, which reported that $99 \%$ of the respondents used BMD assessment to help them diagnose and make treatment decisions for their patients. ${ }^{16}$

Interestingly, in the National Health and Wellness Survey, glucocorticoid use was not significantly predictive of pharmacological treatment for osteoporosis/osteopenia, ${ }^{6}$ and this agrees with findings from a retrospective analysis of pharmacy claims data in which $52.5 \%$ of the patients taking glucocorticoids did not take concomitant anti-osteoporosis medications. ${ }^{17}$ In contrast, in this physician survey, nearly $90 \%$ of physicians regarded glucocorticoid (or other medication) use as a major consideration when treating their female osteoporosis patients.

One factor that could perhaps benefit from more attention is that of a patient's race. Comparatively, few (23.4\%) of the physicians in our survey rated race/ethnicity as a major consideration when treating a female osteoporosis patient. It has been shown that black women of peri and postmenopausal age are less likely to have a BMD test than white women. ${ }^{18}$ In this scenario, black patients might not receive needed bisphosphonate therapy if their physician considers BMD test results at the expense of other patient characteristics. 
The physicians in this study rated their patients' acceptance of bisphosphonates as moderate to strong. These results are consistent with an earlier survey of US women aged $>50$, in which $83 \%$ of women reported being "interested in" osteoporosis pharmacotherapy, and $86 \%$ were "likely to take" the medication when given the information that it provides a $35 \%$ relative fracture risk reduction and the cost is fully covered. ${ }^{13}$ By comparison, only $57 \%$ of women in that study reported being likely to take the medication if they had to pay $10 \%$ of the cost. ${ }^{13}$ Some physicians in our survey were attuned to patients' financial concerns, with $31.0 \%$ reporting affordability as a major reason for noncompliance with bisphosphonates.

The patients treated with bisphosphonates consistently prefer monthly over weekly dosing regimens and weekly over daily regimens, ${ }^{19,20}$ and the physicians' preferences for weekly and monthly dosing schedules in this study complement this finding. According to one review of this topic, less frequent dosing translates into increases of 12\%-29\% in 1-year persistence. ${ }^{19}$ Less frequent dosing has also been shown to decrease the occurrence of gastrointestinal symptoms in patients taking bisphosphonates, ${ }^{21,22}$ which may have implications for patient compliance, given that several studies have found that gastrointestinal symptoms, or the use of gastroprotective agents, are sometimes associated with noncompliance. ${ }^{23-28}$ The physicians in this study identified gastrointestinal intolerance as one of the major reasons for patient noncompliance. Based on these results, physicians in this study seemed aware that prescribing less frequent dosing regimens would improve patient's satisfaction and increase the likelihood of long-term compliance with pharmacotherapy. Likewise, citing medication side effects, most physicians incorporated drug holidays into their management of osteoporosis patients, a practice consistent with the recommendations of national guidelines. ${ }^{3,4}$

Most of the physicians in this study predicted that $\geq 50 \%$ of the patients would comply with their prescribed regimen for $>1$ year. A substantial percentage (21.5\%) even estimated that $\geq 80 \%$ of patients would comply with treatment during year 1 . However, adherence, defined as achieving a medication possession ratio of $80 \%$ or $66 \%$ (similar to our definition of compliance), was observed in only $43 \%$ of the patients over 7-12 months in a pooled analysis of treatment with bisphosphonates, ${ }^{29}$ and medication possession ratios have been shown to decline in years 2 and 3 of bisphosphonate therapy. ${ }^{30}$ This suggests that physicians may be overly optimistic about their patients' actual medication-taking behavior. Indeed, an earlier study comparing physician survey results to actual pharmacy claims data showed that physicians overestimated their patients' 1-year compliance by approximately 20 percentage points $(69.2 \%$ predicted vs $48.7 \%$ actual compliance). ${ }^{15}$

The primary limitation of this study is that the findings are from the perspective of physicians, which is necessarily an indirect measure of patients' experience of treatment with bisphosphonates. In addition, physicians' opinions and perceptions were not compared with actual follow-up data, such as patient compliance over the 1 st and subsequent years. Furthermore, many of the questions included in the survey were qualitative in nature and only broadly assessed management practices. However, the study design provides insight into physicians' practices, preferences, and expectations regarding bisphosphonate treatment and allows comparison with earlier studies of patient-reported and clinical outcomes. Like all claims database analyses, this analysis was subject to potential coding errors or omissions, which may have affected the composition of the study sample. For example, osteoporosis diagnosis codes are notoriously underused, and physicians whose patients lacked such a code but would have otherwise qualified for the survey were not selected. In addition, most patients in the HIRD ${ }^{\mathrm{SM}}$ are Caucasian and all are commercially insured, potentially limiting the generalizability of our findings. Finally, the survey was developed in-house and was not tested with a focus group or validated by comparison to other established survey instruments.

\section{Conclusion}

This study showed that physicians consider the major risk factors for fracture when treating their female osteoporosis patients and are generally attuned to their patients' preferences for treatment. When prescribing bisphosphonates, physicians expect good compliance from their patients, but are familiar with the reasons for noncompliance (ie, gastrointestinal intolerance, side effects, affordability of medication).

\section{Acknowledgments}

The authors thank Anna Kaufman, MPH, and Melissa Stauffer, PhD, in collaboration with SCRIBCO, for medical writing assistance. The study was funded by Merck \& Co., Inc.

\section{Author contributions}

JJS contributed to the design of the study and the development of the survey instrument. JY contributed to the design of the study. TG, DFEL, and JJS managed, analyzed, and 
interpreted the data. All authors contributed toward data analysis, drafting and revising the paper and agree to be accountable for all aspects of the work.

\section{Disclosure}

At the time of the study JY was an employee of Merck \& Co., Inc. JJS and TG are employees of HealthCore, which received funding from Merck \& Co., Inc. to perform the analyses. At the time of the study DFEL was an employee of HealthCore.

\section{References}

1. Looker AC, Borrud LG, Dawson-Hughes B, Shepherd JA, Wright NC. Osteoporosis or low bone mass at the femur neck or lumbar spine in older adults: United States, 2005-2008. NCHS Data Brief. 2012;(93):1-8.

2. Management of osteoporosis in postmenopausal women: 2010 position statement of The North American Menopause Society. Menopause. 2010;17(1):25-54; quiz 55-56.

3. Watts NB, Bilezikian JP, Camacho PM, et al. American Association of Clinical Endocrinologists Medical Guidelines for Clinical Practice for the diagnosis and treatment of postmenopausal osteoporosis. Endocr Pract. 2010;16 Suppl 3:1-37.

4. Cosman F, de Beur SJ, LeBoff MS, et al. Clinician's guide to prevention and treatment of osteoporosis. Osteoporos Int. 2014;25(10): 2359-2381.

5. Siris ES, Modi A, Tang J, Gandhi S, Sen S. Substantial under-treatment among women diagnosed with osteoporosis in a US managed-care population: a retrospective analysis. Curr Med Res Opin. 2014;30(1): 123-130.

6. Meadows ES, Mitchell BD, Bolge SC, Johnston JA, Col NF. Factors associated with treatment of women with osteoporosis or osteopenia from a national survey. BMC Womens Health. 2012;12:1.

7. Imaz I, Zegarra P, Gonzalez-Enriquez J, Rubio B, Alcazar R, Amate JM. Poor bisphosphonate adherence for treatment of osteoporosis increases fracture risk: systematic review and meta-analysis. Osteoporos Int. 2010;21(11):1943-1951.

8. Ross S, Samuels E, Gairy K, Iqbal S, Badamgarav E, Siris E. A metaanalysis of osteoporotic fracture risk with medication nonadherence. Value Health. 2011;14(4):571-581.

9. Diab DL, Watts NB. Bisphosphonates in the treatment of osteoporosis. Endocrinol Metab Clin North Am. 2012;41(3):487-506.

10. Fraser LA, Vogt KN, Adachi JD, Thabane L. Fracture risk associated with continuation versus discontinuation of bisphosphonates after 5 years of therapy in patients with primary osteoporosis: a systematic review and meta-analysis. Ther Clin Risk Manag. 2011;7:157-166.

11. Curtis JR, Westfall AO, Cheng H, Delzell E, Saag KG. Risk of hip fracture after bisphosphonate discontinuation: implications for a drug holiday. Osteoporos Int. 2008;19(11):1613-1620.

12. Neuner JM, Laud PW, Schapira MM. A randomized study of the effect of 5-year and lifetime hip fracture risk information on physician recommendations for management of low bone density. J Clin Densitom. 2007;10(4):370-375.

\section{Clinical Interventions in Aging}

\section{Publish your work in this journal}

Clinical Interventions in Aging is an international, peer-reviewed journal focusing on evidence-based reports on the value or lack thereof of treatments intended to prevent or delay the onset of maladaptive correlates of aging in human beings. This journal is indexed on PubMed Central, MedLine,
13. Sinsky CA, Foreman-Hoffman V, Cram P. The impact of expressions of treatment efficacy and out-of-pocket expenses on patient and physician interest in osteoporosis treatment: implications for pay-for-performance programs. J Gen Intern Med. 2008;23(2):164-168.

14. Weiss TW, Siris ES, Barrett-Connor E, Miller PD, McHorney CA. Osteoporosis practice patterns in 2006 among primary care physicians participating in the NORA study. Osteoporos Int. 2007;18(11):1473-1480.

15. Copher R, Buzinec P, Zarotsky V, Kazis L, Iqbal SU, Macarios D. Physician perception of patient adherence compared to patient adherence of osteoporosis medications from pharmacy claims. Curr Med Res Opin. 2010;26(4):777-785.

16. Ha YC, Lee YK, Lim YT, Jang SM, Shin CS. Physicians' attitudes to contemporary issues on osteoporosis management in Korea. $J$ Bone Metab. 2014;21(2):143-149.

17. Chitre MM, Hayes W. 3-year results of a member and physician intervention to reduce risk associated with glucocorticoid-induced osteoporosis in a health plan. J Manag Care Pharm. 2008;14(3):281-290.

18. Gourlay ML, Callahan LF, Preisser JS, Sloane PD. Osteoporosis preventive care in white and black women in community family medicine settings. South Med J. 2007;100(7):677-682.

19. Reginster JY, Rabenda V. Patient preference in the management of postmenopausal osteoporosis with bisphosphonates. Clin Interv Aging. 2006;1(4):415-423.

20. Bonnick SL, Silverman S, Tanner SB, et al. Patient satisfaction in postmenopausal women treated with a weekly bisphosphonate transitioned to once-monthly ibandronate. $J$ Womens Health (Larchmt). 2009;18(7):935-943

21. Binkley N, Martens MG, Silverman SL, et al. Improved GI tolerability with monthly ibandronate in women previously using weekly bisphosphonates. South Med J. 2009;102(5):486-492.

22. Derman R, Kohles JD, Babbitt A. Gastrointestinal tolerability with ibandronate after previous weekly bisphosphonate treatment. Clin Interv Aging. 2009;4:357-365

23. Berecki-Gisolf J, Hockey R, Dobson A. Adherence to bisphosphonate treatment by elderly women. Menopause. 2008;15(5):984-990.

24. Penning-van Beest FJ, Erkens JA, Olson M, Herings RM. Determinants of non-compliance with bisphosphonates in women with postmenopausal osteoporosis. Curr Med Res Opin. 2008;24(5):1337-1344.

25. Penning-van Beest FJ, Goettsch WG, Erkens JA, Herings RM. Determinants of persistence with bisphosphonates: a study in women with postmenopausal osteoporosis. Clin Ther. 2006;28(2):236-242.

26. Lo JC, Pressman AR, Omar MA, Ettinger B. Persistence with weekly alendronate therapy among postmenopausal women. Osteoporos Int. 2006;17(6):922-928.

27. Yun H, Curtis JR, Guo L, et al. Patterns and predictors of osteoporosis medication discontinuation and switching among Medicare beneficiaries. BMC Musculoskelet Disord. 2014;15:112.

28. Gallagher AM, Rietbrock S, Olson M, van Staa TP. Fracture outcomes related to persistence and compliance with oral bisphosphonates. J Bone Miner Res. 2008;23(10):1569-1575.

29. Kothawala P, Badamgarav E, Ryu S, Miller RM, Halbert RJ. Systematic review and meta-analysis of real-world adherence to drug therapy for osteoporosis. Mayo Clin Proc. 2007;82(12):1493-1501.

30. Martin KE, Yu J, Campbell HE, Abarca J, White TJ. Analysis of the comparative effectiveness of 3 oral bisphosphonates in a large managed care organization: adherence, fracture rates, and all-cause cost. J Manag Care Pharm. 2011;17(8):596-609.

\section{Dovepress}

CAS, Scopus and the Elsevier Bibliographic databases. The manuscript management system is completely online and includes a very quick and fair peer-review system, which is all easy to use. Visit http://www.dovepress. com/testimonials.php to read real quotes from published authors. 